06

\title{
Особенности структуры и свойств тонких пленок цирконата-титаната свинца с сильно неоднородным распределением состава по толщине
}

\author{
() Д.М. Долгинцев ${ }^{1}$, М.В. Старицын ${ }^{1,2}$, В.П. Пронин ${ }^{1}$, Е.Ю. Каптелов ${ }^{1,3}$, С.В. Сенкевич ${ }^{1,3}$, \\ И.П. Пронин ${ }^{1,3, \rrbracket}$, С.А. Немов ${ }^{4}$ \\ ${ }^{1}$ Российский государственный педагогический университет им. А.И. Герцена, Санкт-Петербург, Россия \\ ${ }^{2}$ НИЦ „Курчатовский институт“-Центральный научно-исследовательский институт конструкционных материалов \\ „Прометей“ им. И.В. Горынина, Санкт-Петербург, Россия \\ ${ }^{3}$ Физико-технический институт им. А.Ф. Иофрфе РАН, Санкт-Петербург, Россия \\ ${ }^{4}$ Санкт-Петербургский политехнический университет Петра Великого, Санкт-Петербург, Россия \\ `E-mail: Petrovich@mail.ioffe.ru
}

Поступило в Редакцию 8 мая 2019 г.

В окончательной редакции 8 мая 2019 г.

Принято к публикации 21 мая 2019 г.

\begin{abstract}
При варьировании давления рабочего газа в установке высокочастотного магнетронного распыления осаждались тонкие пленки цирконата-титаната свинца, состоящие из двух слоев, в которых содержание свинца различалось на 20\%. Проведено сравнительное исследование фазового состояния, состава и диэлектрических свойств двухслойных структур, различающихся последовательностью осаждения этих слоев. Показано, что в зависимости от очередности расположения слоев существенно изменяются условия кристаллизации фазы перовскита и униполярные свойства пленок.
\end{abstract}

Ключевые слова: высокочастотное магнетронное распыление, тонкие пленки РZT, неоднородное распределение свинца по толщине.

DOI: 10.21883/PJTF.2019.16.48156.17873

Тонкие сегнетоэлектрические пленки твердых растворов цирконата-титаната свинца $\mathrm{Pb}(\mathrm{Zr}, \mathrm{Ti}) \mathrm{O}_{3}$ (PZT) находят широкое применение в мультиферроиках, в различных областях микроэлектромеханики, инфракрасной техники и в ряде других областей техники [1-3]. Наиболее востребованы пленки составов, соответствующих морфотропной фазовой границе, где электромеханические параметры твердых растворов достигают максимальных значений. Одной из серьезных проблем, препятствующих достижению максимальных параметров пленок, является наличие остаточного (избыточного) свинца в пленке, стимулирующего процессы кристаллизации фазы перовскита. Необходимость добавления избыточного свинца вызвана как его потерями из-за высокой волатильности его оксида, так и тем фактом, что фаза перовскита не образуется при содержании свинца ниже стехиометрического [4-6].

Поскольку зародышеобразование фазы перовскита в реальных условиях происходит либо на интерфейсах тонкой пленки, либо в ее объеме [7-9], достаточно сложно добиться однородного распределения свинца по толщине сегнетоэлектрического слоя. Это связано с тем, что при разрастании перовскитового островка избыточный свинец (обычно в виде оксида) вытесняется на фазовую границу пирохлор-перовскит. В конечном итоге избыток оксида свинца $(\mathrm{PbO})$ локализуется на верхнем или нижнем интерфейсах пленки и на межкристаллических границах, откуда „выдавить“ его затруднительно. Эта структурная неоднородность приводит к локальной неоднородности емкости по площади и толщине пленки, так как диэлектрическая проницаемость оксида свинца $\left(\varepsilon_{\mathrm{PbO}} \sim 10\right)$ по величине на один-два порядка ниже, чем у твердых растворов РZT $\left(\varepsilon_{\text {PZT }} \sim 100-1000\right)$. Это означает, что приложение сильного электрического поля может приводить к неоднородному распределению потенциала по толщине пленки и, как следствие, к микропробоям. Эффективная величина диэлектрической проницаемости такой пленки может быть существенно ниже величины $\varepsilon_{\text {PZT. }}$ С другой стороны, присутствие включений оксида свинца вблизи нижнего интерфейса пленки способствует образованию макроскопического униполярного состояния (самополяризации), что является серьезным преимуществом при создании микроэлектромеханических устройств [10,11].

В связи с этим актуальной задачей является управление составом тонких пленок PZT в процессе осаждения. Один из путей ее решения заключается в варьировании содержания свинца в процессе осаждения пленок и контроле его изменения в процессе кристаллизации фазы перовскита. Задача настоящей работы состоит в изучении структуры и свойств двухслойных тонких пленок PZT с сильно различающимся содержанием свинца в слоях.

Пленки осаждались методом высокочастотного магнетронного распыления на платинированную кремниевую подложку $\left(\mathrm{Pt} / \mathrm{TiO}_{2} / \mathrm{SiO}_{2} / \mathrm{Si}\right)$, а также на подложку в отсутствие $\mathrm{Pt}$-электрода $\left(\mathrm{SiO}_{2} / \mathrm{Si}\right)$. Состав керамической мишени соответствовал области морфотропной фазовой границы с элементным соотношением $\mathrm{Zr} / \mathrm{Ti}=54 / 46$ с добавлением $10 \mathrm{~mol} \%$ PbO. Двухслойные пленки изго- 


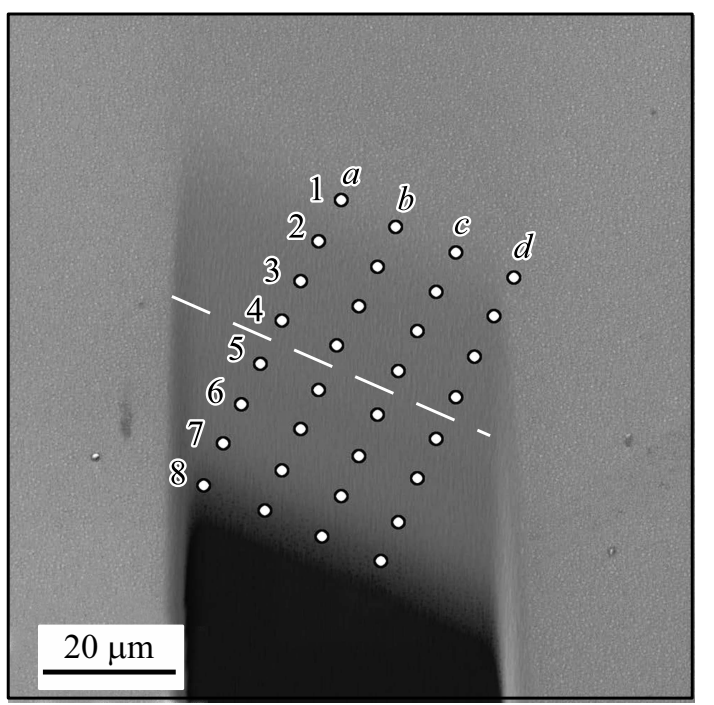

Pис. 1. Изображение окна травления аморфной пленки PZT (структура $A$ ), полученное в растровом электронном микроскопе, и координатное расположение точек, в которых измерялся состав пленки. Увеличение номера ряда соответствует увеличению глубины травления пленки. Штриховая линия соответствует границе между слоями, осажденными при $4 \mathrm{~Pa}$ (нижний слой) и $8 \mathrm{~Pa}$ (верхний слой).

тавливались в двух вариантах: в первом случае $(A)$ нижний слой осаждался при давлении $4 \mathrm{~Pa}$, а верхний слой - при давлении $8 \mathrm{~Pa}$; во втором случае $(B)$ эти слои менялись местами. Изменение давления рабочей газовой смеси $80 \% \mathrm{Ar}+20 \% \mathrm{O}_{2}$ позволяло варьировать содержание свинца в осажденных слоях [6,12]. Время осаждения каждого из слоев составляло $80 \mathrm{~min}$. Общая толщина слоев составляла $920 \mathrm{~nm}$. Синтез фазы перовскита осажденных слоев проводился в печи на воздухе при $T_{c}=550-570^{\circ} \mathrm{C}$.

Фазовое состояние анализировалось с помощью метода растровой электронной микроскопии. Для определения состава использовался растровый электронный микроскоп LYRA 3 (Tescan) с энергодисперсионной приставкой X-Max 80. Состав образцов определялся при сканировании электронным пучком поверхности пленок размером $100 \times 200 \mu \mathrm{m}$. Энергия падающих электронов составляла $12 \mathrm{keV}$. Диэлектрические свойства изучались с помощью автоматизированного комплекса на базе измерителя иммитанса E7-20 и модифицированной схемы Сойера-Тауэра.

Для изучения распределения атомов по толщине сформированных пленок на образцах, осажденных на кремний, были вытравлены „окна“ с наклонной стенкой. Травление производилось пучком ионов $\mathrm{Ga}$ под углом менее $1^{\circ}$, область травления представлена на рис. 1 . Светлая часть пленки представляла собой свободную поверхность, темная часть - поверхность кремния, промежуточная часть - область травления. Измерения состава проводились в локальных точках, отмеченных на рисунке. Глубина травления $t$ увеличивалась с увеличением порядкового номера ряда точек (от 1 до 8). Первый ряд (1) располагался на поверхности пленки. Усреднение состава проводилось по четырем точкам $(a-d)$, находящимся на одной глубине травления.

На рис. 2 показано изменение содержания свинца в осажденных двухслойных PZT-структурах, представленных на вставках. Видно, что на поверхности структуры $A$, в верхнем слое, осажденном при $8 \mathrm{~Pa}$, избыточное (сверхстехиометрическое) содержание свинца достигало $21 \%$ (кривая 1 ). В то же время на поверхности структуры $B$, в верхнем слое, осажденном при $4 \mathrm{~Pa}$, содержание свинца не достигало стехиометрического соотношения $(-1 \%)$. По мере увеличения глубины травления пленки (до $t \sim 400 \mathrm{~nm}$ ) в структуре $A$ относительное содержание свинца монотонно уменьшалось до величины, близкой к стехиометрической (кривая 1). При дальнейшем увеличении глубины травления содержание свинца снижалось, что связано с нарастающим искажением состава в наноразмерных слоях [8]. В структуре $B$ наблюдалась обратная картина (кривая 2). Увеличение содержания свинца наблюдалось при бо́льших значениях $t$, чем на кривой 1 , что связано с различием в толщинах слоев, осажденных при разных давлениях. Аналогично кривой 1 при больших глубинах травления также наблюдалось искажение состава.

Контроль фазового состояния после высокотемпературного отжига пленок, осажденных на платинированную кремниевую подложку, показал, что кристаллизация фазы перовскита была близка к завершению в обеих структурах. При этом в структуре $A$ доля фазы перовскита в объеме пленки составляла $\sim 89 \%$, а в структуре $B-\sim 99 \%$. Различие в объемах фазы перовскита в структурах связано с тем, в какой из структур слой, осажденный при $4 \mathrm{~Pa}$, больше обогащается свинцом. В структуре $A$ избыточный свинец из

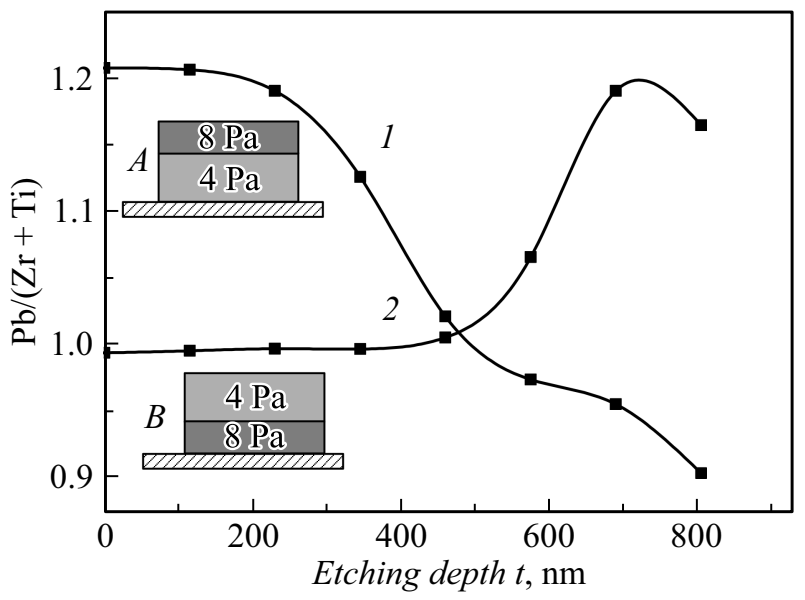

Рис. 2. Изменение содержания свинца (в относительных единицах) в осажденных двухслойных пленках PZT при увеличении глубины травления $t$. Кривые пояснены в тексте. На вставках - схематическое расположение осажденных при 4 и 8 Ра слоев. 

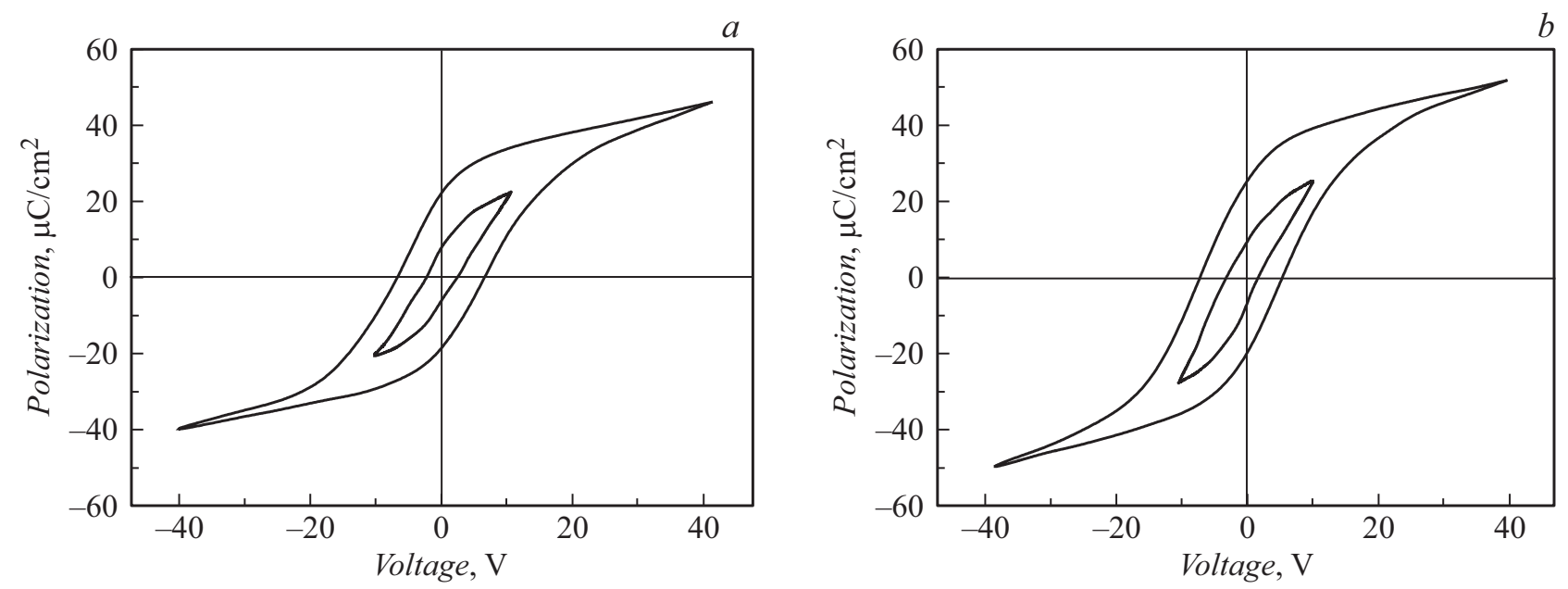

Рис. 3. Петли диэлектрического гистерезиса, полученные на перовскитовых структурах $A(a)$ и $B(b)$. Температура отжига $570{ }^{\circ} \mathrm{C}$. Частота измерения $1 \mathrm{kHz}$.

Содержание свинца $\mathrm{Pb} /(\mathrm{Zr}+\mathrm{Ti})$ (в относительных единицах) в приповерхностных слоях тонких пленок PZT структур $A$ и $B$

\begin{tabular}{c|c|c|c|c|c}
\hline \multicolumn{3}{c|}{ Структура $A$} & \multicolumn{3}{c}{ Структура $B$} \\
\hline $\begin{array}{c}\text { Аморф- } \\
\text { ная фаза }\end{array}$ & $\begin{array}{c}\text { Фаза пи- } \\
\text { рохлора }\end{array}$ & $\begin{array}{c}\text { Фаза пе- } \\
\text { ровскита }\end{array}$ & $\begin{array}{c}\text { Аморф- } \\
\text { ная фаза }\end{array}$ & $\begin{array}{c}\text { Фаза пи- } \\
\text { рохлора }\end{array}$ & $\begin{array}{c}\text { Фаза пе- } \\
\text { ровскита }\end{array}$ \\
\hline 1.21 & 1.14 & 1.07 & 0.99 & 0.94 & 1.02
\end{tabular}

верхнего слоя, осажденного при 8 Ра, вытесняется как в нижнюю, так и в верхнюю часть пленки, испаряясь со свободной поверхности. В структуре $B$ вытеснение свинца из нижнего слоя, осажденного при $8 \mathrm{~Pa}$, по большей части происходит в верхнюю часть пленки; таким образом, в последнем случае потери избыточного свинца оказываются меньше.

Содержание свинца в приповерхностной области аморфных и отожженных пленок приведено в таблице. Видно, что в структуре $A$ в верхнем слое, осажденном при $8 \mathrm{~Pa}$, избыточное содержание свинца снижалось до $\sim 7 \%$, в то время как в фазе пирохлора оно оставалось существенно выше. Это связано с тем, что значительные потери свинца происходят по межфазным границам пирохлор-перовскит в процессе кристаллизации пленок $[9,13]$. В структуре $B$, напротив, перовскитовый слой, осажденный при $4 \mathrm{~Pa}$, обогащается свинцом, в том числе за счет диффузии свинца из фазы пирохлора в фазу перовскита. По всей видимости, аналогичные процессы диффузии свинца происходят и в нижних слоях исследуемых структур.

Сравнение величин эффективной диэлектрической проницаемости образцов $\left(\varepsilon_{e f f}\right)$ показало, что структура $A$ характеризовалась несколько меньшими значениями $\varepsilon_{e f f} \sim 750-800$, чем структура $B$, для которой были характерны более высокие значения $\varepsilon_{e f f} \sim 800-850$. Такое различие обусловлено наличием включений фазы пирохлора в пленках со структурой $A$. Изучение петель диэлектрического гистерезиса (рис. 3) показало, что они несколько различаются по характеру. Величины остаточной поляризации коррелировали со значениями диэлектрической проницаемости и составляли $\sim 21$ и $23 \mu \mathrm{C} / \mathrm{cm}^{2}$ для структур $A$ и $B$ соответственно. При этом петля гистерезиса для структуры $A$ выглядела практически симметричной (рис. $3, a)$, в то время как для структуры $B$ она была смещена в сторону отрицательных напряжений и свидетельствовала о наличии среднего внутреннего поля величиной $\sim 12 \mathrm{kV} / \mathrm{cm}^{2}$ (рис. $3, b$ ). Существование внутреннего поля в двухслойной пленке, где нижний слой, осажденный при $8 \mathrm{~Pa}$, был обогащен избыточным свинцом, и отсутствие такого поля в пленке, где нижний слой характеризовался практически стехиометрическим составом, является подтверждением того, что избыточный оксид свинца, локализованный вблизи нижнего интерфейса пленки, принимает участие в образовании объемного заряда и поляризующего поля.

Таким образом, в работе показано, следующее:

- варьированием давления рабочего газа в установке высокочастотного магнетронного распыления можно формировать тонкие пленки PZT с сильно неоднородным распределением атомов свинца по толщине;

- при кристаллизации фазы перовскита наблюдалось уменьшение элементной неоднородности в результате диффузии атомов свинца в область, обедненную свинцом;

- диэлектрические свойства сформированных двухслойных тонких пленок PZT существенно различаются в зависимости от последовательности расположения слоев с разным содержанием свинца.

\section{Финансирование работы}

Экспериментальные исследования выполнены с использованием оборудования ЦКП НИЦ „Курчатов- 
ский институт“-ЦНИИ КМ „Прометей,, при финансовой поддержке Минобрнауки РФ в рамках соглашения № 14.595.21.0004 (уникальный идентификатор RFMEFI59517X0004).

Работа выполнена в рамках проектной части госзадания (проект № 16.2811.2017/4.6).

\section{Конфликт интересов}

Авторы заявляют, что у них нет конфликта интересов.

\section{Список литературы}

[1] Muralt P. // J. Am. Ceram. Soc. 2008. V. 91. N 5. P. 1385 1396. DOI: $10.1111 / \mathrm{j} .1551-2916.2008 .02421 . \mathrm{x}$

[2] Kang M.-G., Jung W.-S., Kang Ch.-Y., Yoon S.-J. // Actuators. 2016. V. 5. N 1. P. 5 (1-17). DOI: $10.3390 /$ act5010005

[3] Eerenstein W., Mathur N.D., Scott J.F. // Nature. 2006. V. 442. N 7104. P. 759-765. DOI: 10.1038 /nature 05023

[4] Яфбе Б., Кук У., Яффе Г. Пьезоэлектрическая керамика. М.: Мир, 1974. 288 c.

[5] Окадзаки К. Технология керамических диэлектриков. М.: Энергия, 1976. 336 с.

[6] Долгинцев Д.М., Пронин В.П., Каптелов Е.Ю., Сенкевич С.В., Пронин И.П. // Письма в ЖТФ. 2019. Т. 45. В. 6. C. 3-6.

[7] Воротилов К.А., Жигалина О.М., Васильев В.А., Сигов A.C. // ФТТ. 2009. Т. 51. В. 7. C. $1268-1271$.

[8] Хмеленин Д.Н., Жигалина О.М., Воротилов К.А., Лебо И.Г. // ФТТ. 2012. Т. 54. В. 5. С. 939-941.

[9] Пронин В.П., Сенкевич С.В., Каптелов Е.Ю., Пронин И.П. // ФТТ. 2013. Т. 55. В. 1. С. 92-97.

[10] Es-Souni M., Kuhnke M., Iakovlev S., Solterbeck C.-H., Piorra A. // Appl. Phys. Lett. 2005. V. 86. N 2. P. 022907. doi.org/10.1063/1.1851610

[11] Lv P.P., Jiang X.M., Yan J., Hu G.D. // J. Mater. Sci.: Mater. Electron. 2017. V. 28. N 2. P. 2233-2240. doi.org/10.1007/s10854-016-5793-6

[12] Вольпяс В.А., Козырев А.Б., Тумаркин А.В., Долгинцев Д.М., Каптелов Е.Ю., Сенкевич С.В., Пронин И.П. // ФTT. 2019. Т. 62. В. 7. C. $1282-1286$.

[13] Осипов В.В., Киселев Д.А., Каптелов Е.Ю., Сенкевич С.В., Пронин И.П. // ФТТ. 2015. Т. 57. В. 9. С. 1748-1754. 